\title{
Estrogen Receptor Positive and Progesterone Receptor Negative Breast Cancer: the Role of Hormone Therapy
}

\author{
Robert Dembinski ${ }^{1} \cdot$ Vishnu Prasath ${ }^{1} \cdot$ Carisa Bohnak ${ }^{1} \cdot$ Charalampos Siotos $^{1} \cdot$ Mohamad E. Sebai $^{1} \cdot$ Kevin Psoter $^{2}$. \\ Faiz Gani ${ }^{1}$. Joe Canner ${ }^{1}$ - Melissa S. Camp ${ }^{1} \cdot$ Armina Azizi $^{1} \cdot$ Lisa Jacobs $^{1} \cdot$ Mehran Habibi $^{1}$ (I)
}

Received: 14 February 2020 / Accepted: 1 June 2020 / Published online: 9 June 2020

(C) Springer Science+Business Media, LLC, part of Springer Nature 2020

\begin{abstract}
$\mathrm{ER}+\mathrm{PR}-$ (estrogen receptor positive and progesterone receptor negative) tumors constitute only a small portion of the breast cancer population. Patients with ER+/PR- tumors, however, are characterized by worse survival compared to patients with ER+/PR+ (estrogen receptor positive and progesterone receptor positive) tumors. Controversy exists regarding the efficacy of hormone blocking therapy for patients with ER+/PR - tumors. The NCDB was queried between 2004 and 2015, and patients with invasive ER+/PRtumors were identified. We employed univariate Cox proportional hazards to compare outcomes among patients that did or did not receive hormone blocking therapy. We identified 138,398 patients with invasive ER+/PR- tumors, 32,044 (23\%) of whom did not receive hormone blocking therapy. The reasons for not receiving hormone blocking therapy included contraindications to treatment, death, patient refusal, and unknown. There were no significant differences in race, income quartile, or education quartile between patients who did and did not receive hormone blocking therapy. Patients who did not receive hormone blocking therapy underwent surgical assessment of the axilla more frequently than those who did receive hormone therapy. Our analysis demonstrated that hormone blocking therapy administration was associated with increased overall survival for up to 10 years of follow up (HR: 0.58 ; $95 \%$ CI: $0.56-0.59, p<0.001)$. Hormone blocking therapy may be associated with increased survival for breast cancer patients with ER+/PRtumors. Although this benefit may last for years after completion of the course, up to $25 \%$ of patients do not receive this treatment. Strategies to increase the utilization and adherence to hormone blocking therapy regimens may improve patient survival outcomes.
\end{abstract}

Keywords Breast cancer $\cdot$ Hormone therapy $\cdot \mathrm{ER}+/-\cdot \mathrm{PR}+/-$

\section{Introduction}

Among American women, breast cancer is the most common cancer, corresponding to $30 \%$ of all cancers, and is the second largest cause of cancer mortality (15\%) [1]. Currently, research initiatives are focused on the heterogeneity of individual tumors and the role of their distinct histological and clinicopathologic characteristics for the design of personalized treatment plans. Among these characteristics, steroid hormone receptor status has been shown to reliably predict overall outcomes [2-14]. For this reason, the American Joint Commission of Cancer

Mehran Habibi

mhabibi2@jhmi.edu

1 Department of Surgery, Johns Hopkins Hospital, Johns Hopkins University School of Medicine, Bayview Campus, Building A, 5th Floor, 4940 Eastern Avenue, Baltimore, MD 21224, USA

2 Department of Pediatrics, Johns Hopkins Bayview Medical Center, Baltimore, MD, USA formally included hormone status in the updated breast cancer staging system [15]. ER+/PR+ is the most common variant of breast tumors, while $\mathrm{ER}+\mathrm{PR}-$ cases represent approximately only $1.5-3.4 \%$ of patients; this cohort tends to have worse survival outcomes than the former group [2, 8, 16-19].

Targeted hormone receptor therapies, such as Tamoxifen (TAM) and aromatase inhibitors, are well documented to improve the outcomes in breast cancer patients with $\mathrm{ER}+/ \mathrm{PR}+$ disease [20]; [21]. The presence of hormone blocking therapy resistance, however, is one of the potential factors that may be responsible for the observed survival difference between ER+/ $\mathrm{PR}+$ and $\mathrm{ER}+/ \mathrm{PR}-$ patients $[2,18]$. Previous studies have demonstrated that $\mathrm{ER}+\mathrm{PR}-$ patients are less likely to respond to hormone blocking therapy in the metastatic setting [22]. This relationship, however, does not appear to be as significant for patients with early stage disease [23, 24].

While the physiology and extent of the resistance have not been well defined, a possible association with the expression of HER2 proteins has been suggested. [2]. In this context, researchers and clinicians are split regarding the efficacy of 
hormone blocking therapy for patients with $\mathrm{ER}+\mathrm{PR}-$ cancers [25]. The purpose of our study is to better understand the impact of hormone blocking therapy on the overall and progression-free survival of ER+/PR- breast cancer patients. Furthermore, our study will seek to identify groups of patients where hormone blocking therapy is underutilized.

\section{Methods}

\section{Patient Demographics}

Eligible patients treated for breast cancer in the USA between 2004 and 2015 were identified from the National Cancer Database (NCDB) registry. Patients with both ER+/PR+ and $\mathrm{ER}+/ \mathrm{PR}$ - cancers were queried and divided into two categories based on receipt of hormone blocking therapy. We also examined the following variables: age, race, charlson score, insurance carrier, income quartile, education quartile, community residence (urban/rural), patient residence category, type of hospital where they were treated, T stage (0-IV), presence or absence of axillary staging with sentinel lymph node biopsy or axillary lymph node dissection (lymphadenectomy), and margin status. Age over/under 50 years old was used as a proxy for menopausal status, although HER2 status data were only available from 2010 to 2015 .

\section{Statistical Analysis}

Demographic and clinical characteristics of women who received hormone blocking therapy were compared to those that did not receive hormone blocking therapy using Chi squared and Student $t$ tests with unequal variances for categorical and continuous variables, respectively. Kaplan-Meier plots were produced and described the probability of overall or progression-free survival by receipt of hormone blocking therapy; log-rank tests were used to compare treated and untreated groups.

Unadjusted and multivariable Cox proportional hazards regression was used to evaluate the association of hormone blocking therapy status with progression-free and overall survival. Adjusted models included age, race, $\mathrm{T}$ stage, $\mathrm{N}$ stage, receipt of chemotherapy, and receipt of radiation. Individuals entered risk sets at the date of diagnosis and were followed until death or date of cancer recurrence. Individuals who did not experience these outcomes were recorded at their last clinical visit (for overall survival). Proportional hazard assumptions were evaluated through visual inspection of the $\log -\log$ survival curves vs. (log) time and scaled Schoenfeld residual plots over time for each variable. Results of regression models are presented as hazard ratios (HRs) with corresponding 95\% confidence intervals (CIs). A $p<0.001$ was considered statistically significant. All analyses were performed using STATA Version 14.1 (StataCorp, College Station, TX).

\section{Results}

We identified 138,398 female patients with ER+/PR- invasive breast cancer from the registry records of the National Cancer Database (NCDB) between 2004 and 2015. The median time to initiation of hormone blocking therapy was 169 days with IQR (91-249). Patients who did not receive hormone blocking therapy underwent lymphadenectomy more frequently than those who did receive hormone blocking therapy $(p<0.001)$. There were no significant differences in race, income quartile, or education quartile between patients who did and did not receive hormone blocking therapy (Table 1).

We identified 871,857 female patients with ER+/PR+ invasive breast cancer from the registry records of the NCBD between 2004 and 2015. The median time to initiation of hormone blocking therapy was 158 days with IQR (80221). There were no significant differences in race, income quartile, or educational quartile between patients who did and did not receive hormone therapy.

About 106,354 (76.9\%) patients from the ER+/PR- population received hormone blocking therapy, while 32,044 (23.2\%) did not. About 718,351 (82.39\%) patients from the $\mathrm{ER}+\mathrm{PR}+$ population received hormone blocking therapy while $153,506(17.61 \%)$ did not. There was a significant difference between receipts of hormone blocking therapy $(p<0.001)$. Of the ER+/PR- patients that did not receive hormone therapy, $1993(1.4 \%)$ patients had contraindications to receiving hormone blocking therapy, 1553 (1.1\%) patients were prescribed hormone blocking therapy but it was never administered, 5710 (4.1\%) patients refused to receive hormone blocking therapy, and $22,579(16.3 \%)$ patients were not offered hormone blocking therapy for unknown reasons. Two hundred nine patients $(0.2 \%)$ died before administration of hormone blocking therapy and were not included in analysis.

Of the 134,510 ER+/PR- patients, receipt of hormone blocking therapy varied by cancer stage. Stage I (75.24\%), stage II $(80.42 \%)$, and stage III $(80.13 \%)$ patients received hormone blocking therapy at a significantly $(p<0.001)$ higher rate than stage IV (65.12\%) patients. Our unadjusted analysis revealed that $\mathrm{ER}+/ \mathrm{PR}-$ patients who received hormone blocking therapy had a statistically significant improved 10year overall survival compared to those who did not receive hormone blocking therapy (HR: 0.59; 95\% CI: 0.57-0.61, $p<0.001$ ) (Fig. 1). Upon adjustment for cancer stage, receipt of hormone blocking therapy was more strongly associated with improved overall survival (HR: 0.53 ; 95\% CI: $0.52-$ 0.55) (Table 2). Although the benefit of hormone blocking therapy was not as strong in stage IV patients (HR: 0.73) 
Table 1 Clinicopathologic characteristics stratified by use of hormone therapy

\begin{tabular}{|c|c|c|c|c|c|c|c|}
\hline \multirow[t]{2}{*}{ Characteristic } & \multicolumn{2}{|c|}{ No hormone therapy } & \multicolumn{2}{|c|}{ Hormone therapy } & \multirow[t]{2}{*}{$P$ value } & \multicolumn{2}{|l|}{ Total } \\
\hline & $N$ & $\%$ & $N$ & $\%$ & & $N$ & $\%$ \\
\hline Total & 32,044 & 23.2 & 106,354 & 76.9 & N/A & 138,398 & 100.0 \\
\hline Age, years, median (IQR) & $63(53-75)$ & & $61(53-70)$ & & $<0.001$ & $61(53-71)$ & \\
\hline Charlson score & & & & & $<0.001$ & & \\
\hline 0 & 27,059 & 84.4 & 90,294 & 84.9 & & 117,353 & 84.8 \\
\hline 1 & 4041 & 12.5 & 13,269 & 12.5 & & 17,283 & 12.5 \\
\hline$\geq 2$ & 971 & 3.0 & 2791 & 2.6 & & 3762 & 2.7 \\
\hline Insurance status & & & & & $<0.001$ & & \\
\hline Private & 15,190 & 48.4 & 56,856 & 54.2 & & 72,046 & 52.9 \\
\hline Medicare & 1823 & 5.8 & 6481 & 6.2 & & 8304 & 6.1 \\
\hline Medicaid & 13,404 & 42.7 & 38,423 & 36.6 & & 51,827 & 38.0 \\
\hline Other/Unknown & 962 & 3.1 & 3103 & 3.0 & & 4065 & 3.0 \\
\hline Income quartile & & & & & $<0.001$ & & \\
\hline Q1 & 3267 & 10.3 & 9791 & 9.3 & & 13,058 & 9.5 \\
\hline Q2 & 5116 & 16.2 & 16,775 & 15.9 & & 21,891 & 15.9 \\
\hline Q3 & 8608 & 27.2 & 29,225 & 27.7 & & 37,833 & 27.6 \\
\hline Q4 & 14,677 & 46.4 & 49,832 & 47.2 & & 64,509 & 47.0 \\
\hline Education quartile & & & & & $<0.001$ & & \\
\hline Q1 & 4044 & 12.8 & 12,075 & 11.4 & & 16,119 & 11.7 \\
\hline Q2 & 6676 & 21.1 & 21,713 & 20.6 & & 28,389 & 20.7 \\
\hline Q3 & 7828 & 24.7 & 27,011 & 25.6 & & 34,839 & 25.4 \\
\hline Q4 & 13,129 & 41.5 & 44,854 & 42.5 & & 57,983 & 42.2 \\
\hline Tumor stage & & & & & $<0.001$ & & \\
\hline Stage I & 16,713 & 55.2 & 50,796 & 48.7 & & 67,509 & 50.2 \\
\hline Stage II & 9136 & 30.2 & 37,528 & 36.0 & & 46,664 & 34.7 \\
\hline Stage III & 3515 & 11.6 & 14,176 & 13.6 & & 17,691 & 13.2 \\
\hline Stage IV & 923 & 3.1 & 1723 & 1.7 & & 2646 & 2.0 \\
\hline Lymphadenectomy & & & & & $<0.001$ & & \\
\hline No & 3364 & 10.6 & 3865 & 3.6 & & 7229 & 5.3 \\
\hline Yes & 28,426 & 89.4 & 102,171 & 96.4 & & 130,597 & 94.8 \\
\hline
\end{tabular}

N/A not available

compared to stages I-III (HR: 0.50-0.53), receipt of hormone blocking therapy was still significantly associated with improved patient outcomes.

For patients with ER+/PR- cancers, there was no significant difference in receipt of hormone blocking therapy in premenopausal patients $(76.30 \%)$ compared to postmenopausal patients $(76.96 \%)(p<0.03)$. In $\mathrm{ER}+\mathrm{PR}+$ patients, however, $84.40 \%$ of premenopausal patients received hormone blocking therapy compared to $81.77 \%$ of postmenopausal patients $(p<0.001)$.

About 69,014 ER+/PR- patients reported HER2 status from 2010 to 2015 . About 51,652 patients (74.84\%) were HER2-, while 16,128 patients $(23.37 \%)$ were HER2+, and 1604 patients $(2.32 \%)$ were borderline/indeterminant. HER2+ patients had statistically significant survival compared to HER2- patients (HR: 0.79; 95\% CI: 0.74-.84, $p<0.001)$. Borderline patients did not demonstrate a significant difference in survival (HR: 1.10; 95\% CI: 0.94-1.29, $p=$ $0.214)$.

\section{Discussion}

Breast cancer is a heterogeneous disease with varying clinicopathologic characteristics. Estrogen receptors are expressed in two-thirds of breast cancers but only a subset of ER+ tumors are also PR- [26]. Hormone positive breast cancer includes a heterogenous group of malignant cells with varying degrees of receptor representation. The breast gland undergoes several prominent phases during adult life with significant functional, structural, and morphological growth, which is mediated through a complex hormonal mechanism [27]. The interplay 
Fig. 1 Kaplan-Meier survival curves by receipt of hormone therapy. $p<0.001$

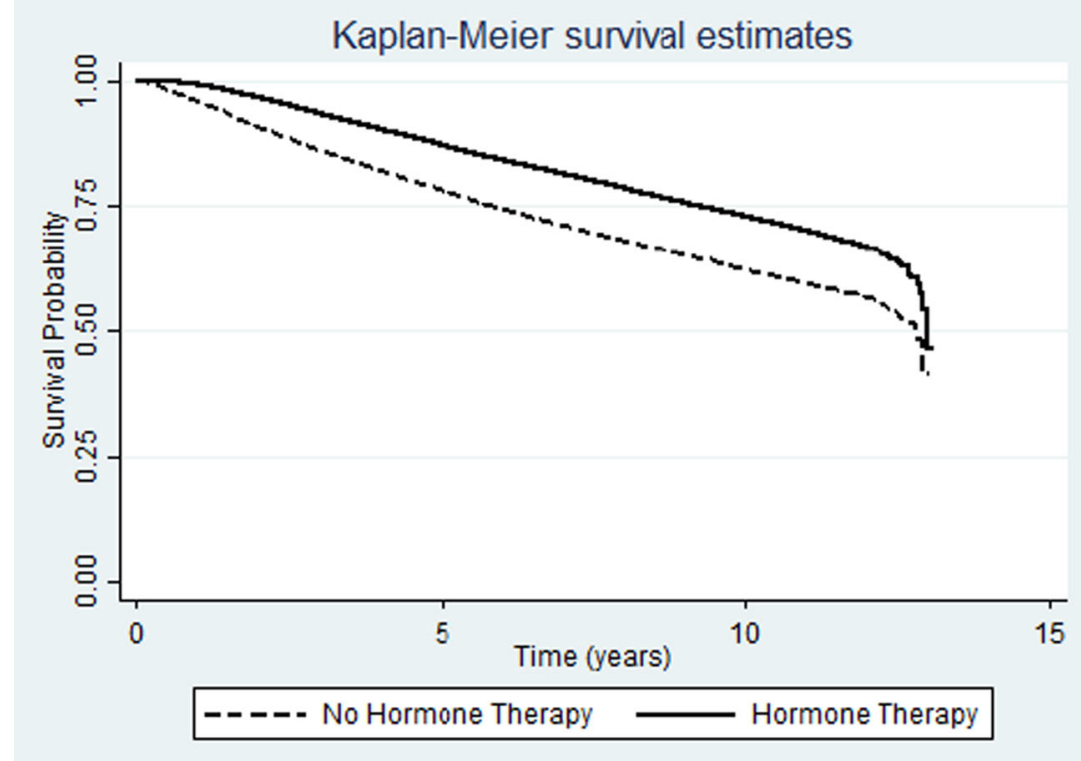

$P$ value: $<0.001$
Table 2 Unadjusted and adjusted Cox proportional hazards regression evaluating the association of selected patient demographic, clinical characteristics, and receipt of hormone therapy and risk of death and progression-free survival in women with $\mathrm{ER}+\mathrm{PR}$ - breast cancer, treated between 2003 and 2017 and registered in NCDB

\begin{tabular}{|c|c|c|c|c|c|c|c|c|}
\hline \multirow[t]{2}{*}{ Characteristic } & \multicolumn{4}{|l|}{ Univariable } & \multicolumn{4}{|l|}{ Multivariable } \\
\hline & Hazard ratio & $95 \% \mathrm{CI}$ & & $P$ value & Hazard ratio & $95 \% \mathrm{CI}$ & & $P$ value \\
\hline \multicolumn{9}{|l|}{ Hormone therapy } \\
\hline No hormone therapy & Reference & - & - & - & Reference & - & - & - \\
\hline Hormone therapy & 0.58 & 0.56 & 0.59 & $<0.001$ & 0.59 & 0.57 & 0.60 & $<0.001$ \\
\hline Age, years & 1.05 & 1.05 & 1.05 & $<0.001$ & 1.06 & 1.05 & 1.06 & $<0.001$ \\
\hline \multicolumn{9}{|l|}{ Patient race } \\
\hline White & Reference & - & - & - & Reference & - & - & - \\
\hline Black & 1.20 & 1.15 & 1.25 & $<0.001$ & 1.25 & 1.19 & 1.30 & $<0.001$ \\
\hline Other/Unknown & 0.65 & 0.60 & 0.71 & $<0.001$ & 0.79 & 0.73 & 0.87 & $<0.001$ \\
\hline \multicolumn{9}{|l|}{ Charlson score } \\
\hline 0 & Reference & - & - & - & Reference & - & - & - \\
\hline 1 & 1.77 & 1.71 & 1.83 & $<0.001$ & 1.42 & 1.37 & 1.47 & $<0.001$ \\
\hline$\geq 2$ & 3.55 & 3.36 & 3.75 & $<0.001$ & 2.44 & 2.30 & 2.59 & $<0.001$ \\
\hline \multicolumn{9}{|l|}{ Insurance status } \\
\hline Private & Reference & - & - & - & - & - & - & - \\
\hline Medicare & 2.08 & 1.97 & 2.20 & $<0.001$ & - & - & - & - \\
\hline Medicaid & 2.77 & 2.96 & 2.85 & $<0.001$ & - & - & - & - \\
\hline Other/Unknown & 1.76 & 1.62 & 1.90 & $<0.001$ & - & - & - & - \\
\hline \multicolumn{9}{|l|}{ Income quartile } \\
\hline Q1 & Reference & - & - & - & - & - & - & - \\
\hline Q2 & 0.93 & 0.89 & 0.98 & 0.004 & - & - & - & - \\
\hline Q3 & 0.86 & 0.82 & 0.90 & $<0.001$ & - & - & - & - \\
\hline Q4 & 0.67 & 0.64 & 0.70 & $<0.001$ & - & - & - & - \\
\hline
\end{tabular}


Table 2 (continued)

\begin{tabular}{|c|c|c|c|c|c|c|c|c|}
\hline \multirow[t]{2}{*}{ Characteristic } & \multicolumn{4}{|l|}{ Univariable } & \multicolumn{4}{|l|}{ Multivariable } \\
\hline & Hazard ratio & $95 \% \mathrm{CI}$ & & $P$ value & Hazard ratio & $95 \% \mathrm{CI}$ & & $P$ value \\
\hline \multicolumn{9}{|l|}{ Education quartile } \\
\hline Q1 & Reference & - & - & - & - & - & - & - \\
\hline Q2 & 0.97 & 0.92 & 1.01 & & - & - & - & - \\
\hline Q3 & 0.91 & 0.88 & 0.96 & $<0.001$ & - & - & - & - \\
\hline Q4 & 0.72 & 0.69 & 0.75 & $<0.001$ & - & - & - & - \\
\hline \multicolumn{9}{|l|}{ Geographic setting } \\
\hline Metropolitan & Reference & & & & & & & \\
\hline Urban & 1.10 & 1.06 & 1.14 & $<0.001$ & - & - & - & - \\
\hline Rural & 1.16 & 1.06 & 1.28 & 0.001 & - & - & - & - \\
\hline \multicolumn{9}{|l|}{ Type of hospital } \\
\hline Community & Reference & - & - & - & Reference & - & - & - \\
\hline Academic/integrated network & 0.82 & 0.81 & 0.85 & $<0.001$ & 0.92 & 0.89 & 0.95 & $<0.001$ \\
\hline \multicolumn{9}{|l|}{ Tumor stage } \\
\hline Stage I & Reference & - & - & - & Reference & - & - & - \\
\hline Stage II & 1.80 & 1.74 & 1.86 & $<0.001$ & 2.03 & 1.96 & 2.10 & $<0.001$ \\
\hline Stage III & 4.03 & 3.90 & 4.18 & $<0.001$ & 4.87 & 4.69 & 5.05 & $<0.001$ \\
\hline Stage IV & 11.54 & 10.93 & 12.18 & $<0.001$ & 12.97 & 12.22 & 13.76 & $<0.001$ \\
\hline \multicolumn{9}{|l|}{ Metastatic disease at diagnosis } \\
\hline No & Reference & - & - & - & - & - & - & - \\
\hline Yes & 6.95 & 6.64 & 7.28 & $<0.001$ & - & - & - & - \\
\hline \multicolumn{9}{|l|}{ Lymphadenectomy } \\
\hline No & Reference & - & - & - & - & - & - & - \\
\hline Yes & 0.31 & 0.30 & 0.32 & $<0.001$ & - & - & - & - \\
\hline \multicolumn{9}{|l|}{ Margin status } \\
\hline Negative & Reference & - & - & - & Reference & - & - & - \\
\hline Positive & 2.08 & 1.99 & 2.17 & $<0.001$ & 1.37 & 1.31 & 1.44 & $<0.001$ \\
\hline
\end{tabular}

and mechanism of action of estrogen, progesterone, and estradiol hormones on breast tissue and breast cancer cells remains elusive. Both hormone deprivation and hormone excess have been associated with cancer cell control and point to the complex mechanism by which the cancer cell growth is modulated [28]. Selective estrogen receptor modulators (SERMs), like Tamoxifen, are standard treatment for hormone receptor positive breast cancer and block the effects of estrogen in breast tissue. The recommended duration of therapy for SERMs is 5 years with a lasting effect up to 20 years [29-33]. For postmenopausal women, aromatase inhibitors like anastrozole are prescribed to block estrogen production, while exemestane is prescribed for women with a history of tamoxifen treatment $[34,35]$.

In our study population there was a difference in receipt of hormone blocking therapy between ER+ patients with PR+ type $(82.39 \%)$ and PR - type $(76.85 \%)$ cancers. Differences in receipt of hormone blocking therapy based on PR receptor status could be attributed to literature describing the reduced effectiveness of hormone blocking therapy in ER+/PR- tumors. A recent study demonstrated a $77 \%$ hormone blocking therapy response rate for $\mathrm{ER}+\mathrm{PR}+$ breast cancers, while ER+/PR - tumors had a response rate of only $27 \%$ [36]. Furthermore, some studies have shown that $30-40 \%$ of patients with $\mathrm{ER}+/ \mathrm{PR}$ - cancers do not respond to targeted hormone blocking therapies [37]. Nonetheless, our study found an improved overall survival in patients with ER+/PR- tumors who received hormone blocking therapy (HR: 0.59). Hormone blocking therapy appears underutilized as 22,579 $(16.3 \%)$ of $\mathrm{ER}+/ \mathrm{PR}-$ patients did not receive hormone blocking therapy for unknown reasons.

Previous studies have described a lack of responsiveness to hormone blocking therapy for ER+/PR - tumors in the metastatic setting but little difference in patients with early stage disease. Our study, however, suggests that hormone blocking therapy is effective in patients with stage IV ER+/PR- cancer. Although patients with stage IV disease had a lesser degree of improvement in survival outcomes compared to stages I-III, receipt of hormone blocking therapy was still associated with improvement in survival for patients with stage IV disease 
(HR: 0.73 ) Of note, just $65.12 \%$ of patients with stage IV $\mathrm{ER}+/ \mathrm{PR}$ - disease received hormone blocking therapy compared to patients with stage I (75.24\%), II (80.42\%), and III $(80.13 \%)$ disease. Since hormone blocking therapy may be associated with improved 10-year survival outcomes in late stage ER+/PR- breast cancer patients, stage IV patients should be considered to receive hormone blocking therapy.

Despite demonstrating clinically relevant survival outcomes, this study has several limitations. The demonstrated improved survival in stage IV patients with ER+ disease may be due to hormone blocking therapy given in combination with CDK4/6 inhibitors in recent years. Despite a statistically significant difference in receipt of hormone therapy between $\mathrm{ER}+/ \mathrm{PR}-$ patients and $\mathrm{ER}+/ \mathrm{PR}+$ patients, a high percentage (17\%) did not receive hormone blocking therapy. The study's retrospective nature prevents insight into the clinical rationale behind the decision to administer or refrain from hormone blocking therapy treatment. Although HER2 protein status can greatly influence treatment plans, this measure was added to the NCDB in 2010 and was limited for this study. Lastly, the NCDB does not report the type of hormone blocking therapy administered, which limits the ability to determine individual drug efficacies and compliance rates.

\section{Conclusion}

Our study is one of the first to compare outcomes of ER+/PRdisease based on the receipt of hormone blocking therapy. The results suggest that hormone blocking therapy may be associated with improved overall and progression-free survival with up to 10 years of follow up. Hormone blocking therapy may be underutilized; however, as nearly $25 \%$ of patients do not receive it. Investigation into the root cause of this underutilization, in conjunction with patient and provider education, could lead to improvement in outcomes for patients with $\mathrm{ER}+/ \mathrm{PR}-$ breast cancer.

\section{Compliance with Ethical Standards}

Conflict of Interest The authors declare that they have no conflict of interest.

\section{References}

1. Siegel RL, Miller KD, Jemal A (2019) Cancer statistics, 2019. CA Cancer J Clin. 69(1):7-34

2. Arpino $\mathrm{G}$ et al (2005) Estrogen receptor-positive, progesterone receptor-negative breast cancer: association with growth factor receptor expression and Tamoxifen Resistance. J Natl Cancer Inst. 97(17):1254-1261

3. Clark GM, McGuire WL (1988) Steroid receptors and other prognostic factors in primary breast cancer. Semin Oncol. 15:20-25
4. Bae SY et al (2015) Poor prognosis of single hormone receptorpositive breast cancer: similar outcome as triple-negative breast cancer. BMC Cancer. 15(1):138

5. Clahsen PC et al (1999) The utility of mitotic index, estrogen receptor and $\mathrm{Ki}-67$ measurements in the creation of novel prognostic indices for node-negative breast cancer. Eur J Surg Oncol. 25(4): 356-363.s

6. McGuir WL (1986) Prognostic factors in primary breast cancer. Cancer Surv. 5(3):527-536

7. Fisher B et al (1988) Relative worth of estrogen or progesterone receptor and pathologic characteristics of differentiation as indicators of prognosis in node negative breast cancer patients: findings from National Surgical Adjuvant Breast and Bowel Project Protocol B-06. J Clin Oncol. 6(7):1076-1087

8. Grann VR et al (2005) Hormone receptor status and survival in a population-based cohort of patients with breast carcinoma. Cancer. 103(11):2241-2251

9. Gasparini G (1998) Prognostic variables in node-negative and node-positive breast cancer. Breast Cancer Res Treat. 52(1-3): 321-331

10. Jensen EV, Jacobson HI (2010) Estrogen action: a historic perspective on the implications of considering alternative approaches. Physiol Behav. 99(2):151-162

11. Jordan VC, Jaspan T (1976) Tamoxifen as an anti-tumor agent: estrogen binding as a predictive test for tumor response. $\mathrm{J}$ Endocrinol. 68(3):453-460

12. Mauri FA et al (1999) Prognostic value of estrogen receptor status can be improved by combined evaluation of $\mathrm{p} 53, \mathrm{Bcl} 2$ and $\mathrm{PgR}$ expression: an immunohistochemical study on breast carcinoma with long-term follow-up. Int J Oncol 15(6):1137-1147

13. Moore DD (2012) A conversation with Elwood Jensen. Annu Rev Physiol. 74(1):1-11

14. Banerjee $\mathrm{M}$ et al (2004) Tree-based model for breast cancer prognostication. J Clin Oncol. 22(13):2567-2575

15. Giuliano AE et al (2017) Breast cancer-major changes in the American Joint Committee on Cancer eighth edition cancer staging manual. CA Cancer J Clin. 67(4):290-303

16. Sun J-Y et al (2016) Progesterone receptor loss identifies hormone receptor-positive and HER2-negative breast cancer subgroups at higher risk of relapse: a retrospective cohort study. OncoTargets Ther. 9:1707-1713

17. Bardou V-J et al (2003) Progesterone receptor status significantly improves outcome prediction over estrogen receptor status alone for adjuvant endocrine therapy in two large breast cancer databases. J Clin Oncol. 21(10):1973-1979

18. Thakkar JP, Mehta DG (2011) A review of an unfavorable subset of breast cancer: estrogen receptor positive progesterone receptor negative. Oncologist. 16(3):276-285

19. Dunnwald LK, Rossing MA, Christopher I Li. (2007) Hormone receptor status, tumor characteristics, and prognosis: a prospective cohort of breast cancer patients. Breast Cancer Res. 9(1):R6

20. Early Breast Cancer Trialists' Collaborative Group (2005) Effects of chemotherapy and hormone therapy for early breast cancer on recurrence and 15-year survival: an overview of the randomized trials. Lancet. 365(9472):1687-1717

21. Lumachi F, Santeufemia DA, Basso SM (1996) Current medical treatment of estrogen receptor-positive breast cancer. Biol Chem. 6(3):231-239

22. Bezwoda WR, Esser JD, Dansey R, Kessel I, Lange M (1991) The value of estrogen and progesterone receptor determinations in advanced breast cancer. Estrogen receptor level but not progesterone receptor level correlates with response to tamoxifen. Cancer. 68(4): $867-872$

23. Early Breast Cancer Trialists' Collaborative Group (2005) Effects of chemotherapy and hormone therapy for early breast cancer on 
recurrence and 15-year survival: an overview of the randomized trials. Lancet. 365(9472):1687-1717

24. Dowsett $\mathrm{M}$ et al (2006) Benefit from adjuvant tamoxifen therapy in primary breast cancer patients according estrogen receptor, progesterone receptor, EGF receptor and HER2 status. Ann Oncol. 17(5): $818-826$

25. Goldhirsch A et al (2009) Thresholds for therapies: highlights of the St Gallen International Expert Consensus on the primary therapy of early breast cancer 2009. Ann Oncol. 20(8):1319-1329

26. Lopez-Tarruella S, Schiff R (2007) The dynamics of estrogen receptor status in breast cancer: re-shaping the paradigm. Clin Cancer Res. 13(23):6921-6925

27. Chlebowski RT, Aragaki AK, Anderson GL (2015) Menopausal hormone therapy influence on breast cancer outcomes in the Women's Health Initiative. J Natl Compr Cancer Netw. 13(7): 917-924

28. Tharmapalan P, Mahendralingam M, Berman HK, Khokha R (2019) Mammary stem cells and progenitors: targeting the roots of breast cancer for prevention. EMBO J. 38(14):e100852

29. King M-C, Wieand S, Hale K, Lee M, Walsh T, Owens K, Tait J et al (2001) Tamoxifen and breast cancer incidence among women with inherited mutations in BRCA1 and BRCA2: National Surgical Adjuvant Breast and Bowel Project (NSABP-P1) Breast Cancer Prevention Trial. Jama. 286(18):2251-2256

30. Fisher B, Costantino JP, Lawrence Wickerham D, Cecchini RS, Cronin WM, Robidoux A, Bevers TB et al (2005) Tamoxifen for the prevention of breast cancer: current status of the National Surgical Adjuvant Breast and Bowel Project P-1 study. J Natl Cancer Inst. 97(22):1652-1662

31. Vogel VG, Costantino JP, Lawrence Wickerham D, Cronin WM, Cecchini RS, Atkins JN, Bevers TB et al (2006) Effects of tamoxifen vs raloxifene on the risk of developing invasive breast cancer and other disease outcomes: the NSABP Study of Tamoxifen and Raloxifene (STAR) P-2 trial. Jama. 295(23):2727-2741

32. Vogel VG, Costantino JP, Lawrence Wickerham D, Cronin WM, Cecchini RS, Atkins JN, Bevers TB et al (2010) Update of the national surgical adjuvant breast and bowel project study of tamoxifen and raloxifene (STAR) P-2 trial: preventing breast cancer. Cancer Prev Res. 3(6):696-706

33. Cuzick J, Sestak I, Cawthorn S, Hamed H, Holli K, Howell A, Forbes JF, Investigators IBIS-I (2015) Tamoxifen for prevention of breast cancer: extended long-term follow-up of the IBIS-I breast cancer prevention trial. Lancet Oncol. 16(1):67-75

34. Goss PE, Ingle JN, Alés-Martínez JE, Cheung AM, Chlebowski RT, Wactawski-Wende J, McTiernan A et al (2011) Exemestane for breast-cancer prevention in postmenopausal women. $\mathrm{N}$ Engl J Med. 364(25):2381-2391

35. Cuzick J, Sestak I, Forbes JF, Dowsett M, Knox J, Cawthorn S, Saunders C et al (2014) Anastrozole for prevention of breast cancer in high-risk postmenopausal women (IBIS-II): an international, double-blind, randomized placebo-controlled trial. Lancet. 383(9922):1041-1048

36. Osborne CK, Schiff R, Arpino G, Lee AS, Hilsenbeck VG (2005) Endocrine responsiveness: Understanding how progesterone receptor can be used to select endocrine therapy. Breast. 14(6):458-465

37. Di G-h, Wu J, Lu J-s, Shen K-w, Liu G-y, Shen Z-z, Shao Z-M (2008) Breast cancer patients with estrogen receptor-negative/progesterone receptor-positive tumors: being younger and getting less benefit from adjuvant tamoxifen treatment. J Cancer Res Clin Oncol. 134(12):1347-1354

Publisher's Note Springer Nature remains neutral with regard to jurisdictional claims in published maps and institutional affiliations. 